\title{
Epidemiological Description of Chikungunya Virus Outbreak in Dire Dawa Administrative City, Eastern Ethiopia, 2019
}

\section{Dessalegn Geleta*, Neammin Tesfaye, Habtamu Ayigegn, Abate Waldetensai, Fekadu Gemechu, Hiwot Amare}

Ethiopian Public Health Institute, Addis Ababa, Ethiopia

\section{Email address:}

geletadessalegn@yahoo.com (D. Geleta), neamintesfaye2123@gmail.com (N. Tesfaye), hayigegn@gmail.com (H. Ayigegn), abyw.res31@gmail.com (A. Waldetensai), fekadu_geme@yahoo.com (F. Gemechu), hiwotamare20@gmail.com (H. Amare)

${ }^{*}$ Corresponding author

\section{To cite this article:}

Dessalegn Geleta, Neammin Tesfaye, Habtamu Ayigegn, Abate Waldetensai, Fekadu Gemechu, Hiwot Amare. Epidemiological Description of Chikungunya Virus Outbreak in Dire Dawa Administrative City, Eastern Ethiopia, 2019. International Journal of Clinical and Experimental Medical Sciences. Vol. 6, No. 3, 2020, pp. 41-45. doi: 10.11648/j.ijcems.20200603.13

Received: May 11, 2020; Accepted: May 28, 2020; Published: June 28, 2020

\begin{abstract}
Chikungunya virus (CHIKV) is an arbovirus transmitted to humans by Aedes mosquitoes. It is one of the epidemic vector-borne diseases which has recently re-emerged, mainly in Asian and African continents and has led to a significant global public health problem in these countries. In Ethiopia the Chikungunia outbreak was reported from Dire Dawa Administrative City on July 2019. Therefore this paper is to document and highlight the epidemiology of chikungunia outbreak in Dire Dawa Administrative City. The Data was analyzed from line list collected by Regional Health Bureau from different public and private health sectors during the course of the outbreak, July 29, 2019 to October 20, 2019. Accordingly, the total of 41162 suspected cases of Chikungunia with 16 laboratory confirmed cases were reported from the City Administration. All of the suspected cases fulfill the standard case definition of Chikungunya. The outbreak starts at one kebeles and finally affected whole part of the city. The median age of the patient is 25 years. The overall attack rate of the outbreak was $12.3 \%$ with zero case fatality rate. The outbreak affected all age groups and both sexes. However, females are more affected than males with an attack rate of $12.32 \%$ and $6.19 \%$ for female and male respectively. Higher attack rate was reported from 15 to 44 age group ( $\mathrm{AR}=50.35 \%)$. Fever $(99.9 \%)$, headache $(99.4 \%)$, joint pain $(99.3 \%)$ and back pain $(87.7 \%)$ are the major clinical symptoms observed during the outbreak.
\end{abstract}

Keywords: Chikungunya, Outbreak, Dire Dawa, Ethiopia

\section{Introduction}

Chikungunya virus (CHIKV) is an arbovirus transmitted to humans by Aedes mosquitoes. The virus was first described in 1952 during a febrile illness outbreak in Makonde, a province in southern Tanzania [1]. It is one of the epidemic vector-borne diseases which has recently re-emerged, mainly in Asian and African continents and has led to a significant global public health problem in these countries [3, 4]. Aedes aegypti and Aedes albopictus are the two Aedes species commonly responsible for transmission $[3,5,6]$.

In Africa, the virus is maintained in a sylvatic transmission cycle between non-human primates, small mammals (eg, bats and monkeys), and Aedes mosquitoes [8]. Outbreak of CHIKV is usually associated with heavy rainfall and subsequent spillover of the virus from an enzootic forest cycle to an epizootic savannah or woodland cycle. Rural outbreaks occur when mosquito populations increase in areas where populations of non-immune people are present [11].

Chikungunya infection typically causes fever and severe and persistent joint pain [7]. Other additional symptoms include nausea, vomiting, chills, headaches and rashes. It is rarely a life threatening infection and treatment is mainly symptomatic. Clinical manifestations of CHIKV fever show some overlap with, and must be distinguished from dengue fever, as well as juvenile rheumatoid arthritis, rubella, and 
several other febrile diseases [9].

Chikungunya infection is diagnosed on the basis of clinical, epidemiological, and laboratory criteria. An acute onset of fever and severe arthralgia or arthritis that is not explained by other medical disorders is considered as a possible CHIKV case. The case becomes probable if the patient has lived in or visited epidemic areas $[10,11,25]$.

Eastern Ethiopia has been recurrently affected by Dengue fever since September 2013 especially during the rainy season. Vector survey conducted in this area also identified the abundance of Aedes aegypti, the vector responsible for both Dengue Fever and Chigungunya Fever transmission [12-14]. At the end of July 2019, local authorities from Dire Dawa Administrative city, the Eastern part of Ethiopia reported unknown febrile illness with joint pain. In response to this, Ethiopian Public Health Institute deployed investigation team to the area to conduct epidemiologic investigation. Consequently, 12 samples tested positive for chikungunya by reversetranscriptase polymerase chain reaction (RT-PCR) at national laboratory. Total of 41162 suspected cases of Chikungunya with 16 laboratory confirmed cases were reported from Dire Dawa Town from July 29, 2019 to October 20, 2019. Therefore this paper documents the outbreak of Chikungunya reported in Dire Dawa Administrative City, Easter Ethiopia highlighting the epidemiology of the outbreak. With this junction, the objective of this analysis is to describe the outbreak, identify the at-risk population and monitor the trend of the outbreak.

\section{Material and Methods}

The study was conducted at Dire Dawa Administrative city which is located in the Eastern of Addis Ababa at Latitude $9031^{\prime} \mathrm{N}$ and Longitude 410 52' $\mathrm{E}$. It is about $515 \mathrm{Km}$ far from capital city of Ethiopia, Addis Ababa which is surrounded by Ethio-somali and Oromia region. The area of the city administration is $1,213 \mathrm{Km}^{2}$, with annual temperature of is $25.9^{\circ} \mathrm{C}$. The health service coverage of the city is $100 \%$.

Data was obtained from line list collected by Dire Dawa Administrative City Health Bureau from different public and private health sectors during the course of the outbreak. The outbreak period was from 29 July 2019 to 20 October 2019. All suspected cases fulfilling the standard case definition of Chikungunya were included in this analysis.

Suspected cases: is a person with acute onset of fever and severe arthralgia or arthritis not explained by other medical conditions, and who resides or has visited epidemic or endemic areas within 2 weeks before the onset of symptoms.

Probable case: is a patient meeting both the clinical and epidemiological criteria Confirmed case: a patient meeting the laboratory criteria, irrespective of the clinical presentation.

Data was cleaned by Microsoft Excel and exported to SPSS 23 statistical software for analysis. Further it is described based on person, place and time. Descriptive analysis was applied to calculate Rate, ratio and proportion for interested parameters.

\section{Result}

\subsection{Epidemiologic Investigation}

Dire Dawa City is endemic for AFI like malaria. The city had been affected by recurrent Dengue Fever outbreak starting from 2013 especially during the rainy season (July to September). At the end of July 2019 unknown AFI like illness with fever and joint pains was reported from kebeles 6 (local smallest administrative unit) to Dire-Dawa administrative city health Bureau. Soon after, experts from Ethiopian Public Health Institute (EPHI) deployed to the area to conduct epidemiologic investigation to the affected area. Subsequently, 12 samples tested positive for chikungunya by reverse-transcriptase polymerase chain reaction (RT-PCR). Therefore, the total of 41162 suspected cases of Chikungunia with 16 laboratory confirmed cases were reported from Dire Dawa Town during the outbreak. All suspected cases have fulfilled the case national definition of Chikungunia.

\subsection{Epidemiology and Clinical Description of the Case}

All of the suspected cases used for this analysis fulfill the standard case definition of Chikungunya. The median age of the patient is 25 years (with age range from 1 month to 98 years) and standard deviation of 16. A total of 41 cases have preexisting comorbidity, 23 Diabetes and 18 hypertensive patients. Only five pregnant women have visited health facility for chikungunya during the outbreak period. Almost all cases were treated at public health facilities, $40242(97.76 \%)$ and $920(2.34 \%)$ were treated at private health facilities. The mean date of onset of the first symptoms and seeking the medical care is 1 day with standard deviation of 1.64. As most of the Chikungunya illness is self-limiting illness and less fatal, almost all of the patients are treated at OPD level. Only 563 $(1.63 \%)$ of the cases are admitted to receive inpatient treatment (Table 1). Age group of 15 to 44 is the most affected part of the population with an attack rate of 50.35 in percent.

Table 1. Characteristics of Chikungunia cases and attack rate of suspected Chikungunia during the outbreak in Dire Dawa city.

\begin{tabular}{|c|c|c|c|c|}
\hline Characteristics & Categories & Case $(\%) n=41162$ & Population & Attack rate in $\%$ \\
\hline \multirow{4}{*}{ Age group } & 45 Years and above & $5809(14.11 \%)$ & 47191 & 12.31 \\
\hline & 15 to 44 & $25277(61.41 \%)$ & 50203 & 50.35 \\
\hline & 5 to 14 & $6821(16.57 \%)$ & 147931 & 4.61 \\
\hline & Under 5 & $3255(7.91 \%)$ & 89361 & 3.64 \\
\hline \multirow{2}{*}{ Sex } & $\mathrm{F}$ & $20450(49.68 \%)$ & 166004 & 12.32 \\
\hline & M & $20712(50.32)$ & 168682 & 6.19 \\
\hline \multirow{3}{*}{ Attended health care facility } & Public Hospital & $11386(27.66 \%)$ & & \\
\hline & Private clinic & $688(1.67 \%)$ & & \\
\hline & Health Center & $28856(70.10 \%)$ & & \\
\hline
\end{tabular}




\begin{tabular}{llll}
\hline Characteristics & Categories & Case (\%) $\mathbf{n = 4 1 1 6 2}$ & Population \\
\hline \multirow{2}{*}{ Type of care } & Outpatient & $40599(98.63 \%)$ & Attack rate in\% \\
\hline
\end{tabular}

The first case were reported from kebeles 6 (the smallest local administrative unit) of the Dire Dawa City administration at the end of July 2019 which later affected the whole nine kebeles with the total attack rate of 12.3. Among the nine kebeles of Dire Dawa City, kebeles 2 was the most affected area with an attack rate of 27.47. The most affected age group are those fall with the rage of 15 to 44 years age and under five contributed least to the total cases during the outbreak.

Table 2. The Attack Rate of Chikungunya in different Kebeles of Dire Dawa City, 2019.

\begin{tabular}{llll}
\hline Kebele & Case $(\mathbf{\%}) \mathbf{n}=\mathbf{4 1 1 6 2}$ & Population & Attack Rate in\% \\
\hline Kebele 1 & $369(0.9 \%)$ & 17,461 & 2.11 \\
Kebele 2 & $17556(42.65 \%)$ & 63,917 & 27.47 \\
Kebele 3 & $2189(5.32 \%)$ & 29,388 & 7.45 \\
Kebele 4 & $2917(7.09 \%)$ & 31,326 & 9.31 \\
Kebele 5 & $4660(11.32 \%)$ & 26,663 & 17.48 \\
\hline
\end{tabular}

\begin{tabular}{llll}
\hline Kebele & Case $(\boldsymbol{\%}) \mathbf{n = 4 1 1 6 2}$ & Population & Attack Rate in\% \\
\hline Kebele 6 & $2735(6.64 \%)$ & 24,813 & 11.02 \\
Kebele 7 & $1051(2.55 \%)$ & 33,451 & 3.14 \\
Kebele 8 & $2764(6.71 \%)$ & 43,632 & 6.33 \\
Kebele 9 & $6921(16.81 \%)$ & 64,036 & 10.81 \\
Total & 41162 & 334,686 & 12.30 \\
\hline
\end{tabular}

The outbreak starts at the end of July reaching its peak on $24^{\text {th }}$ august after which it showed sinusoidal decrement of cases. Starting from $24^{\text {th }}$ August, the case starts to decline for three consecutive weeks up to $2^{\text {nd }}$ September, where it became 223 cases $\left(-42 \%\right.$ case change per day) at the $1^{\text {st }}$ September. The $3^{\text {rd }}$ September was marked with the highest case change rate per day with increment of 1339 (75\%) cases making the second peak of the outbreak. It's after this day that case began to decrease and become almost nil on $20^{\text {th }}$ October (Figure 1).

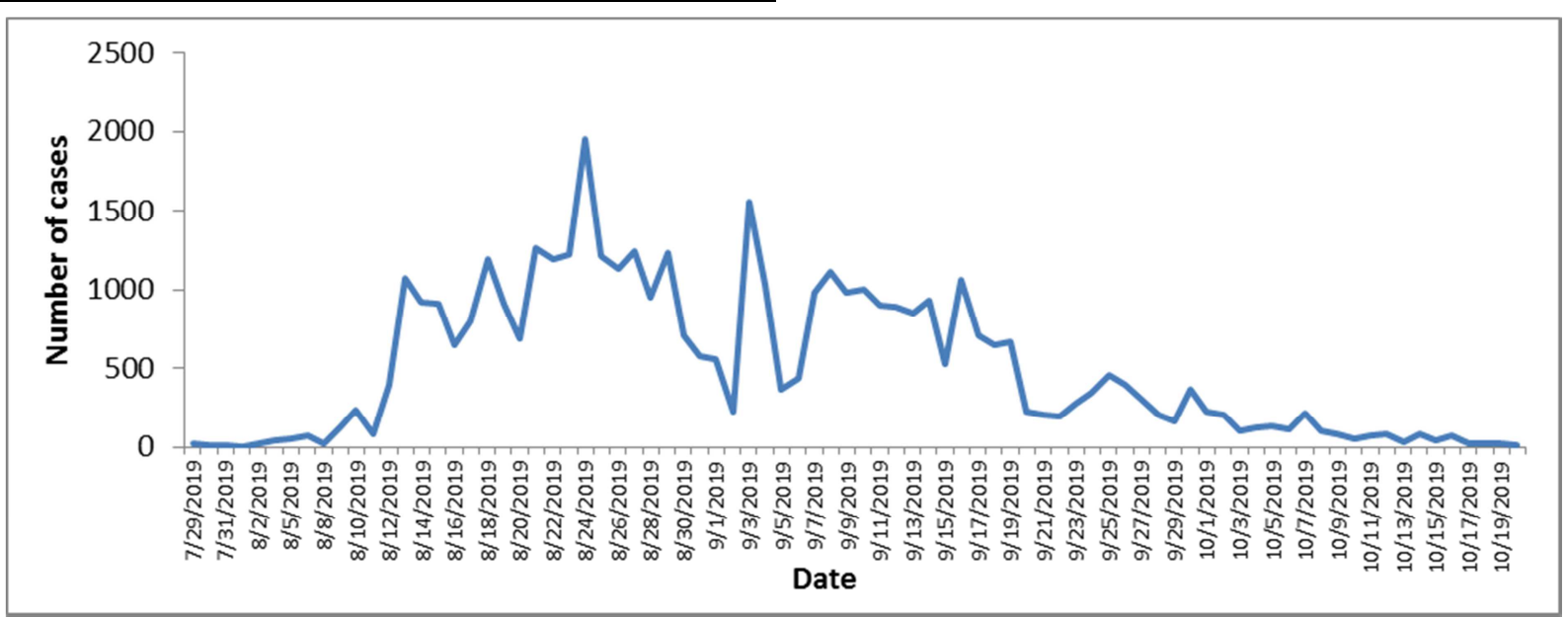

Figure 1. Distribution of suspected Chikungunia cases in Dire Dawa City during the outbreak course.

Almost all patients during physical examination are presented with Fever (99.98\%), joint pain (99.4\%) and headache $(99.3 \%)$ as shown in the following table (Table 1$)$. Back pain is also the commonest symptom presented on $87.7 \%$ of the patient. The other rarely recorded symptoms include vomiting $(0.9 \%)$, rash $(0.2 \%)$ and nasal bleeding $(0.1 \%)$.

Table 3. Clinical features observed on 41162 suspected Chikungunia outbreak in Dire Dawa Administrative City during July to October 2019.

\begin{tabular}{lll}
\hline Clinical features & Response & $\mathbf{\% ,}, \mathbf{n}=\mathbf{4 1 1 6 2}$ \\
\hline Fever & Yes & $41155(99.98 \%)$ \\
& No & $7(0.02 \%)$ \\
joint pain & Yes & $40929(99.4 \%)$ \\
& No & $233(0.6 \%)$ \\
headache & Yes & $40861(99.3 \%)$ \\
& No & $301(0.7 \%)$ \\
back pain & Yes & $36104(87.7 \%)$ \\
& No & $5058(13.3 \%)$ \\
vomiting & Yes & $356(0.9 \%)$ \\
& No & $40806(99.1 \%)$ \\
Rash & Yes & $96(0.2 \%)$ \\
\hline
\end{tabular}

\begin{tabular}{lll}
\hline Clinical features & Response & $\mathbf{\%}, \mathbf{n}=\mathbf{4 1 1 6 2}$ \\
\hline \multirow{3}{*}{ Nasal bleeding } & No & $41066(99.8 \%)$ \\
& Yes & $60(0.1 \%)$ \\
& No & $41102(99.9 \%)$ \\
\hline
\end{tabular}

\section{Discussion}

The first documented Chikungunia outbreak in Ethiopia was reported in June 2016 in the Somali Region of Ethiopia, which borders Mandera County, Kenya [14]. For the second time Chikungunia outbreak occurred in Eastern part of Ethiopia in late July, 2019. This paper documents the first outbreak of Chikungunia reported in Dire Dawa Administrative City, Easter Ethiopia highlighting the epidemiology of the outbreak.

During this outbreak more than forty thousand people has been affected with total attack rate of $12.3 \%$. Kebele 02 is the most affected geographic area with an attack rate of $27.47 \%$ among the nine existing kabeles of Dire Dawa City. All cases 
are reported from urban kebeles. This might be due to poor all inclusive active case search, misdiagnosis at the rural kebeles health centers or poor health seeking behavior of rural community since symptoms of Chikungunia is selflimiting.

Chikungunia affected both gender and all age group in Dire Dawa city. However, female are more affected than male during the outbreak course. This is in line with other studies conducted in different areas [27-30]. Chikungunia attack rate was highest among individual aged 15 to 44 $(\mathrm{AR}=50.35 \%)$ and lowest among under five children $(\mathrm{AR}=3.64 \%)$.

As shown on the epidemic curve (Graph 1), the outbreak was gradually raising before reaching the plateau which lasts about four weeks, indicating a continuous common source epidemic. The second peak of the epidemic is also observed on $3^{\text {rd }}$ September, which may indicate delayed public health measure in responding to the outbreak.

The major clinical symptoms during the acute onset of Chikungunya including Fever (99.9\%), headache (99.4\%), joint pain (99.3\%) and back pain (87.7\%) observed in this analysis is similar to those described in previous studies for acute Chikungunia virus [15-19]. Other gastrointestinal manifestation (vomiting and diarrhea) are rare manifestation of Chikungunia fever except in case of malaria co infection [19-22]. Similarly in our finding vomiting is reported in 356 $(0.9 \%)$ of the patient. Hemorrhagic manifestations including, bleeding, petechiae and/ or skin rashes were generally uncommon in the Chikungunia cases during earlier outbreak episodes worldwide $[18,19,22]$. In this analysis skin rash and bleeding manifestation was observed in $96(0.2 \%)$ and 60 $(0.1 \%)$ of the patient respectively.

In terms of severity no death was reported during the outbreak with CFR of zero. The CFR measure the quality of care, which is premised on timely and definitive diagnosis and also represents the killing power of the disease. The finding of this analysis suggests that Chikungunia is selflimiting and less fatal, in consistence with other findings [11, $16]$.

\section{Limitation}

Several limitations should be high lightened when considering the result. The analysis might underestimates the burden since solely depends on the cases that sought at health facility taking aside the asymptomatic cases with in the community. Only sixteen cases are laboratory confirmed cases due to limited resource to conduct large scale laboratory investigation. Therefore, large scale serological studies capable of detecting the seroconversion rates of these populations will be useful in capturing true incidence. Given the area is also endemic for malaria and Dengue Fever, which are the top deferential diagnosis of Chikungunia, considering all the cases as Chikungunia is also another limitation need to be considered. Even though the country has been giving Field epidemiology training health for surveillance officer, surveillance quality reported cases with their respective symptoms was dependent on surveillance officer. The responsible Aedes mosquito hasn't been also identified.

\section{Conclusion}

For the second time Chikungunia outbreak occurred in Eastern part of Ethiopia in late July, 2019. Total of 41162 suspected cases of Chikungunia with 16 laboratory confirmed cases were reported from Dire Dawa Town during the outbreak. The median age of the patient is 25 years. The overall attack rate of the outbreak was $12.3 \%$ with zero case fatality rate. The outbreak affects all age groups and both sex. However, age group between 15 to 44 and female sex are more affected than others. Fever, Headache, joint pain and back pain are the most clinical symptoms presented during physical examination.

Ethical consideration

Written letter was submitted to Ethiopian Public Health Institute (EPHI), Public Health Emergency Management Center (cPHEM) and permission to use the line list for analysis was obtained both in EPHI and Dire Dawa city administration health bureau.

\section{Authors Contribution}

DG was principally involved in data analysis, write up, selection of articles, and manuscript preparation and revision. NT, HA and the first authors contributed to data analysis, drafting or revising the article, gave final approval of the version to be published and agreed to be accountable for all aspects of the work.

\section{Disclosure}

The authors report no conflicts of interest in this work.

\section{Acknowledgements}

We would like to give our appreciation to Ethiopian Public Health Institute and Dire Dawa City Administration Health Bureau for giving us permission to use the line list for analysis.

\section{References}

[1] Robinson MC. An epidemic of virus disease in Southern Province, Tanganyika Territory, in 1952-53. I. Clinical features. Trans R Soc Trop Med Hyg. 1955; 49 (1): 28-32.

[2] De Lamballerie X, Leroy E, Charrel RN, Ttsetsarkin K, Higgs S, et al. (2008) Chikungunya virus adapts to tiger mosquito via evolutionary convergence: a sign of things to come? Virol J 5: 33 .

[3] Jupp PG, McIntosh BM (1988) Chikungunya virus disease. In: Monath TP (Ed.), The arbovirus: epidemiology and ecology. CRC Press, Inc, Boca Raton, FL, 2: 137-157. 
[4] Powers AM, Logue $\mathrm{CH}$ (2007) Changing patterns of chikungunya virus: reemergence of a zoonotic arbovirus. J Gen Virol 88: 2363-2377.

[5] Jupp PG, McIntosh BM (1990) Aedes furcifer and other mosquitoes as vectors of chikungunya virus at Mica, northeastern Transvaal, South Africa. J Am Mosq Control Assoc 6: 415-420.

[6] Word Health Organization (WHO). Chikungunya. Fact sheet. Updated April 2017. 2017 [updated 2019 Mai 15; cited 2019 Mai 15]. Available from: http://www.who.int/mediacentre/factsheets/fs327/en/.

[7] Diallo M, Thonnon J, Traore-Lamizana M, Fontenille D. Vectors of chikungunya virus in Senegal: current data and transmission cycles. Am J Trop Med Hyg 1999; 60: 281-86.

[8] Mohan A (2006) Chikungunya fever: clinical manifestations \& management. Indian J Med Res 124: 471-474.

[9] WHO. Guidelines for prevention and control of chikungunya fever. http://www.searo.who.int/LinkFiles/Publication_SEACD-182.pdf (accessed Aug 01, 2011).

[10] Burt FJ, Rolph MS, Rulli NE, Mahalingam S, Heise MT. Chikungunya: a re-emerging virus. Lancet (London, England). 2012 Feb; 379 (9816): 662-671. DOI: 10.1016/s01406736(11)60281-x.

[11] AHMED YM \& SALAH AA 2016. Epidemiology of dengue fever in Ethiopian Somali region: retrospective health facility based study. Cent Afr J Public Health; 2: 51-56.

[12] Woyessa Ab, Mengesha M, Kassa W, K. E., Wondabeku M \& Girmay A 2013. Tefrst acute febrile illness investigation associated with dengue fever in Ethiopia,: a descriptive analysis. Ethiop J Health Dev 2014; 28: 155-161.

[13] Degife lh, worku y, belay d, bekele a, hailemariam z. Factors associated with dengue fever outbreak in dire dawa administration city, october, 2015, ethiopia - case control study. 2019; $1-7$.

[14] bitstream/handle/10665/275741/OEW44-271002112018.pdf. WHO 2019. World Health Organization (WHO). Weekly Bulletin on Outbreaks and other Emergencies. Week 38: 16-22 september 22 September 2019.

[15] Simião, Adriana Rocha et al. "A major chikungunya epidemic with high mortality in northeastern Brazil." Revista da Sociedade Brasileira de Medicina Tropical 52 (2019): e20190266.

[16] Thabet AAK, Al-Eryani SMA, Aziz NA, Obadi M, Saleh M, et al. (2013) Epidemiological Characterization of Chikungunya Outbreak in Lahj Governorate, Southern Yemen. J Community Med Health Educ 3: 247. doi: 10.4172/21610711.1000247 .
[17] Cunha RVD, Trinta KS. Chikungunya virus: clinical aspects and treatment - A Review. Mem Inst Oswaldo Cruz. 2017; 112 (8): 523-531. doi: 10.1590/0074-02760170044.

[18] Simon F, Javelle E, Oliver M, Leparc-Goffart I, Marimoutou C (2011) Chikungunya virus infection. Curr Infect Dis Rep 13: 218-228.

[19] Sow A, Faye O, Diallo M, et al. Chikungunya Outbreak in Kedougou, Southeastern Senegal in 2009-2010. Open Forum Infect Dis. 2017; 5 (1): ofx259. Published 2017 Dec 2. doi: 10.1093/ofid/ofx259.

[20] Borgherini G, et al. Outbreak of chikungunya on Reunion Island: early clinical and laboratory features in 157 adult patients. Clinical Infectious Diseases 2007; 44: 1401-1407.

[21] Taubitz W, et al. Chikungunya fever in travellers: Clinical presentations and course. Clinical Infectious Diseases 2007; 45: e1-4.

[22] Kennedy AC, Fleming J, Solomon L. Chikungunya viral arthropathy: a clinical description. Journal of Rheumatology 1980; 7: 231-236.

[23] Beltrame A, et al. Imported Chkungunya infection, Italy. Emerging Infectious Diseases 2007; 13: 1264-1266.

[24] Josseran L, Paquet C, Zehgnoun A, Caillere N, Le Tertre A, et al. (2006) Chikungunya disease outbreak, Reunion Island. Emerg Infect Dis 12: 1994- 1995.

[25] Martins HAL, Bernardino SN, Ribas KH, Santos CC, Antunes $\mathrm{T}$, et al. (2016) Outbreak of Neuro-Chikungunya in Northeastern Brazil. J Neuroinfect Dis 7: 218. doi: 10.4172/2314-7326.1000218.

[26] Rodriguez-Morales AJ, Gil-Restrepo AF, Ramírez-Jaramillo V, Montoya-Arias CP, Acevedo Mendoza WF, Bedoya-Arias JE, et al. Post-chikungunya chronic inflammatory rheumatism: results from a retrospective follow-up study of 283 adult and child cases in La Virginia, Risaralda, Colombia. F1000Research. 2016; 5: 360 .

[27] Economopoulou, A., Dominguez, M., Helynck, B., Sissoko, D., Wichmann, O., Quenel, P., Germonneau, P. And Quatresous, I. (2009) "Atypical Chikungunya virus infections: clinical manifestations, mortality and risk factors for severe disease during the 2005-2006 outbreak on Réunion," Epidemiology and Infection. Cambridge University Press, 137 (4), pp. 534-541. doi: 10.1017/S0950268808001167.

[28] Quatresous I (2006) E-alert 27 January: Chikungunya outbreak in Reunion, a French overseas department. Euro Surveill 11: E060202.1. 